\title{
Health information technology in ambulatory care in a developing country
}

Ghasem Deimazar ${ }^{1}$, Mehdi Kahouei ${ }^{2}$, Afsane Zamani ${ }^{3}$, Zahra Ganji ${ }^{3}$

\begin{abstract}
${ }^{1}$ M.Sc. of Medical Informatics, Lecturer, Department of Health Information Technology, Faculty of Paramedics, Semnan University of Medical Sciences, Semnan, Iran

${ }^{2} \mathrm{Ph} . \mathrm{D}$. of Health Information Management, Associate Professor, Social Determinants of Health Research Center, Semnan University of Medical Sciences, Semnan, Iran

${ }^{3}$ B.Sc. of Health Information Technology, Student Research Committee, Faculty of Paramedics, Semnan University of Medical Sciences, Semnan, Iran
\end{abstract}

\section{Type of article: Original}

\begin{abstract}
Background: Physicians need to apply new technologies in ambulatory care. At present, with regard to the extended use of information technology in other departments in Iran it has yet to be considerably developed by physicians and clinical technicians in the health department.

Objective: To determine the rate of use of health information technology in the clinics of specialist- and subspecialist physicians in Semnan city, Iran.

Methods: This was a 2016 cross-sectional study conducted in physicians' offices of Semnan city in Iran. All physicians' offices in Semnan (130) were studied in this research. A researcher made and Likert-type questionnaire was designed, and consisted of two sections: the first section included demographic items and the second section consisted of four subscales (telemedicine, patient's safety, electronic patient record, and electronic communications). In order to determine the validity, the primary questionnaire was reviewed by one medical informatics- and two health information management experts from Semnan University of Medical Sciences. Utilizing the experts' suggestions, the questionnaire was rewritten and became more focused. Then the questionnaire was piloted on forty participants, randomly selected from different physicians' offices. Participants in the pilot study were excluded from the study. Cronbach's alpha was used to calculate the reliability of the instruments. Finally, SPSS version 16 was used to conduct descriptive and inferential statistics.

Results: The minimum mean related to the physicians' use of E-mail services for the purpose of communicating with the patients, the physicians' use of computer-aided diagnostics to diagnose the patients' illnesses, and the level of the physicians' access to the electronic medical record of patients in the other treatment centers were $2.01,3.58$, and 1.43 respectively. The maximum mean score was related to the physicians' use of social networks to communicate with other physicians (3.64). The study showed that the physicians used less computerized systems in their clinic for the purpose of managing their patients' safety and there was a significant difference between the mean of the scores $(\mathrm{p}<0.001)$

Conclusion: The results showed that the physicians used some aspects of health information technology for the reduction of medical risks and increase of the patient's safety, by collecting the medical data of patients and the rapid and apropos recovering of them for adaptation of clinical decisions.

Keywords: Health information technology, Ambulatory care, Electronic health record
\end{abstract}

\section{Introduction}

The ever-increasing development of information technology has affected the health and treatment department in a similar way to other departments. Technology development has created a noticeable change in treatment and medical care during the past years. Modern medicine and technology are so integrated that physicians need to use these technologies for the purpose of treatment and diagnosis of the illnesses. Nowadays, the growth and

\section{Corresponding author:}

Associate Professor Dr. Mehdi Kahouei, Social Determinants of Health Research Center, Semnan University of Medical Sciences, Semnan, Iran. Tel: +98.2333611587, Fax, Email: mkahouei@yahoo.com

Received: February 25, 2017, Accepted: October 12, 2017, Published: February 2018

iThenticate screening: October 12, 2017, English editing: December 12, 2017, Quality control: December 15, 2017

This article has been reviewed / commented by three experts

(C) 2018 The Authors. This is an open access article under the terms of the Creative Commons Attribution-NonCommercialNoDerivs License, which permits use and distribution in any medium, provided the original work is properly cited, the use is non-commercial and no modifications or adaptations are made. 
development of technology in communication, telecommunications and informatics has resulted in a remarkable evolution in the system of the rendering of health services, too. Furthermore, the different methods of information technology are helping the development of this department, such as the system of saving patients' medical treatment and surgery information, pursuing treatment, telemedicine, surgical robots, patient acceptance and the other systems that the common purpose of which, is the facilitation of treatment affairs (1). During the several past decades, health information technology (HIT) has been increasingly incorporated into the health care process and has been used expansively $(2,3)$. Initially, HIT was used for material and management purposes; but nowadays health care presenters have been associated to it for the apropos and rapid access to health information because of challenges which have been created in regard to health care (4). Therefore, it is difficult to imagine the health care system without information and communication technology. With regard to this matter, HIT is applied for the purpose of automatizing affairs such as sequencing, diagnosis, electronic process of insurance claims, real time adjustment of bills, electronic tracing of bills and health status of patients (1). Therefore, many studies have been done on the acceptance and use of information technology in regard to health. For instance, information technology causes the reduction of medicinal and pharmaceutical risks $(5,6)$, improvement of care quality (7-9), increased patient safety (10), improvement of prevention services and increased patient satisfaction (11) and reduction of health care costs $(10,12)$. In a research done by Hsu et al. for the purpose of studying the effect of health information technology and patient-physician interactions during ambulatory visits, the results showed that by applying HIT in the interactions between the physician and the patient, there were positive effects with regard to the satisfaction with the visit, the communication about the medical decisions and the patient's understanding of medicine decisions (13). Also, in a study done by Hing et al., for the purpose of collecting information about the acceptance of electronic medical records among physicians, it was revealed that $34.8 \%$ of physicians used the system of full-electronic or semielectronic medical records, that this statistic shows the increase in an amount of $19.2 \%$ from 2006 and $91.2 \%$ from 2001. The physicians in the medical institutes, of whom there were more than $11,(74.3 \%)$ were more inclined to use the Electronic Medical Record (EMR) while the physicians in small medical institutes $(20.6 \%)$ were less inclined to use these systems. The centers which had several specialists $(52.5 \%)$ were more inclined to use the EMR, while its use was less in the clinics with one physician or one kind of specialty (30.3\%) (14). Another study was done by Rittenbouse et al., with the aim of studying the increased acceptance of HIT and its use in small offices of care. The results of this study illustrated that physicians had electronic access to patients' laboratory results, clinical data and drug information from their office with the rate of $83 \%, 66 \%$ and $43 \%$ respectively. Furthermore only $21 \%$ of physicians used E-mail to communicate with their patients (15). A research done by Kahouei et al. in Semnan city, reported the lack of integrity of clinical information systems in medical issues as the main obstacle to using computers in clinical areas. As many as 55.6\% selected the increasing of awareness towards a clinical information system as the first solution to increase doctors' willingness to use information technology (16). As such, physicians need to apply new technologies in ambulatory care. To date, with regard to the extended use of information technology in the other departments in Iran, it is yet to be considerably developed by physicians and clinical technicians in the health department; while, applying this technology causes further realization of treatment purposes, presentation of better services and access to the information at the minimum amount of time, increased patients' satisfaction, increased efficiency of the system and decreased possible costs. Therefore, the use of this technology in the health department would result in the peremptory movement toward a better and vivid future, and the health care organizations should familiarize themselves to these systems to overcome the initial challenges in their application. Therefore, since clinical staff (e.g. physicians) are one of the important groups in using HIT in the medical field, studying the present situation about the rate of physicians using new technology seems necessary. Indeed, the support of HIT by clinical staff (e.g. physicians, nurses etc.) can lead to the extensive use of this technology. Thus, these questions can be asked; due to the extension of information technology in the health sector in developed and developing countries, how is the rate of using telemedicine services in ambulatory care centers of Semnan city? Also, due to the existence of health information systems in hospitals throughout Iran and Semnan, what is the rate of use of the patient's electronic health record? Also, if clinical staff use it, how much has it affected patients' safety management? As such, this study aimed to assess the amount of use of health information technology in the clinics of specialist and subspecialist physicians in Semnan city.

\section{Material and Methods}

This was a cross-sectional study conducted in physicians' offices in Semnan city, Iran. The research was carried out from April to December, 2016. The target offices are equipped with clinical information systems. All of the physicians' offices in Semnan (130) were studied in this research. Thus, no sampling procedure was used. A Likerttype questionnaire was used for collecting data. This instrument, which was designed based on the available literature, consisted of two sections: the first section included demographic items such as age, gender, work 
experience, and specialty. The second section consisted of four subscales. The first subscale aimed at measuring the use of telemedicine (6 questions), the second subscale, which tapped into management of patients' safety includes 5 questions, the third subscale measured electronic patient records (5 questions); and the fourth subscale aimed at measuring electronic communications, includes 8 questions (Table 1).

Table 1. Mean score of physician's attitude about using HIT in physician's offices

\begin{tabular}{|c|c|c|c|c|c|}
\hline & Questions & Mean & SD & $\begin{array}{l}\text { Mean } \\
\text { rank }\end{array}$ & $\begin{array}{l}\mathrm{p}- \\
\text { value }\end{array}$ \\
\hline \multirow[t]{6}{*}{ Telemedicine } & $\begin{array}{l}\text { How much do you use computer systems and Internet in your } \\
\text { office? }\end{array}$ & 2.99 & 1.301 & 5.86 & \multirow[t]{6}{*}{$<0.001$} \\
\hline & $\begin{array}{l}\text { How much do you use information and communication technology } \\
\text { (ICT) for telemedicine services? }\end{array}$ & 2.27 & 1.18 & 4.14 & \\
\hline & How much do you use teleconsultation services for your patients? & 2.60 & 1.23 & 4.90 & \\
\hline & How much do you use Email services for consulting your patients? & 2.01 & 1.05 & 3.65 & \\
\hline & $\begin{array}{l}\text { How much do you do teleconsultation with other specialists in your } \\
\text { office about your patients? }\end{array}$ & 2.96 & 1.16 & 5.69 & \\
\hline & $\begin{array}{l}\text { How much do you use mobile health systems (such as smart } \\
\text { phones) to communicate with your patients in order to follow up } \\
\text { patient care? }\end{array}$ & 2.54 & 1.30 & 4.76 & \\
\hline \multirow[t]{5}{*}{$\begin{array}{l}\text { Patient safety } \\
\text { management }\end{array}$} & $\begin{array}{l}\text { How much do you rely on telemedicine services in terms of patient } \\
\text { safety? }\end{array}$ & 3.51 & 0.977 & 4.68 & \multirow[t]{5}{*}{$<0.001$} \\
\hline & $\begin{array}{l}\text { How much do computer systems and application software increase } \\
\text { patient safety in your opinion? }\end{array}$ & 3.44 & 0.964 & 4.58 & \\
\hline & $\begin{array}{l}\text { How much do you use computer systems to check drug interactions } \\
\text { according to patients' age and weight in your office? }\end{array}$ & 2.77 & 1.23 & 3.57 & \\
\hline & $\begin{array}{l}\text { How much do you use computer systems to check drug side effects } \\
\text { and drug contraindications for patients in your office? }\end{array}$ & 2.95 & 1.24 & 3.91 & \\
\hline & $\begin{array}{l}\text { How much do you use diagnosis assistance systems (e.g. artificial } \\
\text { intelligence systems, expert systems) in your office to diagnose } \\
\text { your patients' diseases? }\end{array}$ & 1.54 & 0.909 & 1.76 & \\
\hline \multirow[t]{5}{*}{$\begin{array}{l}\text { Electronic Health } \\
\text { Record }\end{array}$} & $\begin{array}{l}\text { How much do you use electronic medical records in your office for } \\
\text { patients? }\end{array}$ & 1.97 & 1.40 & 3.51 & \multirow[t]{5}{*}{$<0.001$} \\
\hline & $\begin{array}{l}\text { How much do you register patients' medication orders } \\
\text { electronically in your office? }\end{array}$ & 1.62 & 1.17 & 3.12 & \\
\hline & $\begin{array}{l}\text { How much do you register patients' laboratory test orders } \\
\text { electronically in your office? }\end{array}$ & 1.69 & 1.22 & 3.26 & \\
\hline & $\begin{array}{l}\text { How much do you register patients' imaging orders electronically } \\
\text { in your office? }\end{array}$ & 1.88 & 1.38 & 3.45 & \\
\hline & $\begin{array}{l}\text { How much do you access patients' electronic medical records in } \\
\text { other centers from your office? }\end{array}$ & 1.43 & 0.907 & 2.97 & \\
\hline \multirow[t]{8}{*}{$\begin{array}{l}\text { Electronic } \\
\text { Communication }\end{array}$} & $\begin{array}{l}\text { How much do you use online social networks to communicate with } \\
\text { your patients? }\end{array}$ & 2.33 & 1.30 & 4.65 & \multirow[t]{8}{*}{$<0.001$} \\
\hline & $\begin{array}{l}\text { How much do you use social networks (e.g. Telegram, Viber, Line, } \\
\text { etc.) to communicate with other physicians? }\end{array}$ & 3.64 & 1.12 & 6.87 & \\
\hline & $\begin{array}{l}\text { How much do you use Email services to communicate with other } \\
\text { specialists? }\end{array}$ & 2.91 & 1.23 & 5.87 & \\
\hline & $\begin{array}{l}\text { How much do you communicate electronically with other medical } \\
\text { centers (e.g. hospitals, clinics, etc.) from your office? }\end{array}$ & 2.01 & 1.15 & 4.03 & \\
\hline & $\begin{array}{l}\text { How much do you use electronic systems to access patients' } \\
\text { imaging reports (e.g. radiology, CT scan, sonography, MRI, etc.)? }\end{array}$ & 2.18 & 1.31 & 4.30 & \\
\hline & $\begin{array}{l}\text { How much do you communicate electronically with pharmacies (to } \\
\text { prescribe patients' drug medication electronically)? }\end{array}$ & 1.51 & 0.874 & 3.06 & \\
\hline & $\begin{array}{l}\text { How much do you use electronic systems in your office to access } \\
\text { patients' laboratory results (electronic communication with } \\
\text { laboratory)? }\end{array}$ & 1.52 & 0.874 & 3.09 & \\
\hline & $\begin{array}{l}\text { How much do you communicate electronically with insurance } \\
\text { organizations for patients' reimbursement? }\end{array}$ & 2.06 & 1.23 & 4.13 & \\
\hline
\end{tabular}


The answers on each item were measured on a 5-point Likert type scale, never $=1$, very low $=2$, low $=3$, high $=4$ and very high $=5$. In order to determine the validity, the primary questionnaire was reviewed by one medical informatics and two health information management experts from Semnan University of Medical Sciences. Utilizing the experts' suggestions, the questionnaire was rewritten and became more focused. Then the questionnaire was piloted on forty participants, randomly selected from different physicians' offices. Participants in the pilot study were excluded from the study. Cronbach's alpha was used to calculate the reliability of the instruments, with the results indicating indices of 0.707 for the telemedicine section, 0.724 for the section of management of patient's safety, 0.872 for the section of electronic health record, and 0.808 for the electronic communications section. Next, further revisions were made and some statements were rephrased. Lastly, the final version of the anonymous questionnaire was distributed among the research community $(\mathrm{n}=130)$ who were working in hospitals, and they were asked to complete the questionnaire. Furthermore, SPSS (version 16) was used to conduct descriptive and inferential statistics in a similar way to the Friedman test. First, we obtained ethical approval from the Medical Ethics Committee of Semnan University (IR.SEMUMS.REC.1394.164). Then, we prepared a cover letter describing the purposes of the study. The letter explained that responding to the survey indicated the participants' consent to take part in the research. It also assured the participants that all responses would be kept confidential.

\section{Results}

The results of the present study showed that of a total 130 people of the statistic population, 95 people (73.07\%) participated in this study. Of these participants, 75 people $(78.9 \%)$ were specialists and 20 people $(21.2 \%)$ were subspecialists. The average of the individuals' age and the mean of their work experience were 43.26 years and 12.93 years, respectively (Table 2 ). The minimum mean related to the physicians' use of E-mail services for the purpose of communicating with the patients was 2.01 .

Table 2. The study participants' characteristics

\begin{tabular}{|l|l|l|l|}
\hline Variables & $\mathrm{n}$ & $\%$ \\
\hline \multirow{4}{*}{ Sex } & Female & 59 & 62.1 \\
\cline { 2 - 4 } & Male & 39 & 37.9 \\
\hline \multirow{3}{*}{ Education } & Expert & 75 & 78.9 \\
\cline { 2 - 4 } & Specialist & 20 & 21.2 \\
\hline \multirow{5}{*}{} & Pediatrician & 14 & 14.4 \\
\cline { 2 - 4 } & Neurology and psychiatry & 5 & 5.3 \\
\cline { 2 - 4 } & Internist & 15 & 15.8 \\
\cline { 2 - 4 } & Surgery & 12 & 12.6 \\
\cline { 2 - 4 } & Radiology & 6 & 6.3 \\
\cline { 2 - 4 } & Dermatology & 5 & 5.3 \\
\cline { 2 - 4 } & Gynecology & 6 & 6.3 \\
\cline { 2 - 4 } & Dentistry & 9 & 9.5 \\
\cline { 2 - 4 } & Other & 23 & 24.2 \\
\hline Age (year) $($ Mean \pm SD) & $43.26 \pm 9.22$ & & \\
\hline Work experience $($ year) $($ Mean \pm SD) & $12.93 \pm 9.77$ & & \\
\hline
\end{tabular}

The other results revealed that the physicians used the distance consulting services with other physicians, regarding their patients. Also, there was a significant difference between the mean of the scores $(\mathrm{p}<0.001)($ Table 1$)$. The findings relating to the amount of the physicians' use of health information technology in the management of the patient's safety, showed that the maximum mean score related to the system of electronic record of medical orders in the reduction of pharmaceutical interference and the minimum mean score related to the physicians' use of Computer-Aided Diagnostics to diagnose the patients' illnesses, have the scores of 3.58 and 1.54, respectively. The study results showed that the physicians used less computerized systems in their clinic for the purpose of managing their patients' safety and there was a significant difference between the mean of the scores $(\mathrm{p}<0.001)($ Table 1$)$. The findings related to the electronic health record (Table 1) showed that the minimum mean score (1.43) was related to the level of the physicians' access to the electronic medical record of patients in the other treatment centers. The study results revealed that the physicians did not use the specialist systems extensively in their clinics. Also, there was a significant difference between the mean of the scores $(\mathrm{p}<0.001)$. Respecting the electronic communications (Table 1), the results express that the maximum mean score was related to the physicians' use of social networks to communicate with the other physicians (3.64) and the minimum mean score was related to the electronic communication of physicians with the pharmacies from the clinic, and there was a significant difference between the 
mean scores $(\mathrm{p}<0.001)$. The other findings of the present study showed that the maximum and minimum mean scores in the use of HIT were related to the management of the patients' safety and electronic health record, respectively (Figure 1).

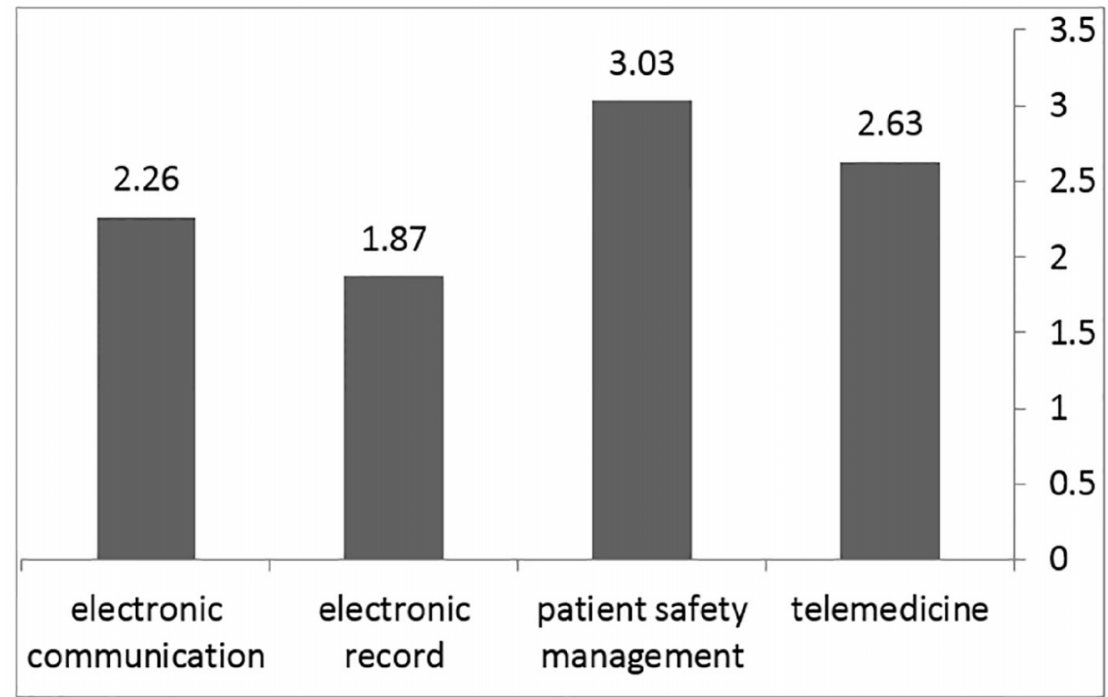

Figure 1. Average score of the use of HIT by physicians for Ambulatory care in different scopes

\section{Discussion}

\subsection{Telemedicine}

The findings relating to the amount of the physicians' use of telemedicine services revealed that the physicians in the ambulatory care centers limitedly used these services for their patients. It seems that the physicians were less willing toward the use of cellphones to pursue the long-distance care of their patients. The results showed that the physicians could not apply the health information technology in ambulatory care in the interactions of a physician with the patient, and were not able to increase the patient's satisfaction with the visit, improve the communication related to the medical decisions or extol the patient's understanding of these decisions (13). In fact, telemedicine can improve the management of severe illnesses. Also, it can reduce the unnecessary references of the patients and the treatment costs (17). The other findings of the present study showed that most of the physicians did not use E-mail for the purpose of long-distance consulting with their patients. These findings are dissimilar to the study of Gaster and his co-workers in 2003 who showed that $72 \%$ of the physicians used E-mail services for communicating with their patients (18). Perhaps, the reason most Iranian physicians do not use communicational technology is the lack of patients' access to proper internet, or the patients' not using E-mail, or the lack of reimbursement for long-distance consulting services for Iranian physicians. The results of the study done by Brown et al. showed that the use of electronic communications was limited in clinical care centers, such that just $30.5 \%$ of physicians communicated with their patients using E-mail (19).

\subsection{Management of patient's safety}

The results of this research showed that some of the physicians believed that the use of health information technology in ambulatory care centers causes the reduction of medical risks and increases the patients' safety. Nevertheless, some physicians had never used computerized systems in their clinic for the study of pharmaceutical interferences with regard to the age and weight of the patient. This could be due to the fact that there is no national pharmaceutical database in Iran for physicians to check pharmaceutical interferences and cases of the prohibition of consumption of drugs; this has resulted in an increase of risk and ultimately, the reduction of the level of patient safety (20 At the time physician is ordering, the CPOE with having CDSS (21) can reduce pharmaceutical errors and increase patient safety by checking drug interactions and allergies, and also calculating the drug dose with regard to patient's information such as his/her age and weight (22).

\subsection{Electronic Health Record}

According to the research findings, most of the physicians did not record their pharmaceutical orders $(\mathrm{Mean}=1.62)$, the requests of the patient's experiments (Mean=1.69) or requests of the patients' radiology $(\mathrm{Mean}=1.88)$ in an 
electronic form. The physicians recorded their orders on paper and most of the information of ambulatory patients was not recorded and the physicians could not survey the clinical antecedents of their patients in the subsequent visits of patients. This similar to the results of the study done by DesRoches et al., who showed that physicians recorded $95 \%$ of pharmaceutical orders and $68 \%$ of requests of patients' tests in an electronic form that this matter led to the physicians' access to all pharmaceutical antecedents and tests of the patients, in necessary situations (23). The research results showed that Iranian physicians were not so inclined to use the electronic record. This matter reveals a lack of the physicians' knowledge of abundant advantages of electronic health record (such as apropos access to all clinical information such as the patients' prescription history, patients family medical history, sensitivities and allergies of patients, test results of patients, surgery and the other services to patients).

\subsection{Electronic communications:}

According to the research findings, the physicians rarely used online social networks (mean= 2.33) for communicating with their patients, despite the fact that the physicians and patients' personal use of online social networks are going to be extensively developed. The reason for this, is the lack of reimbursement for telemedicine services and lack of the physicians' tendency toward applying this technology. However, $48.8 \%$ of the physicians used online social networks for the purpose of communicating with other physicians. In this regard, a study was done by Brown et al., and its results showed that just $21.2 \%$ of physicians believed that social networks are suitable for communication between physician and patient. Also, the other results of the present study showed that most of the physicians used social networks for personal use (19). The results of this study showed that most of the physicians did not record pharmaceutical orders, requests of patient's tests or requests of radiology of patients in an electronic form in their clinic. It is for this reason that the computerized systems of the physicians' clinics did not communicate electronically with pharmacies, laboratories and radiography centers. Therefore, the physicians had no electronic access to the test results and reports of radiology and pharmaceutical prescriptions of their patients in necessary situations and for this reason, they are not able to constantly check the clinical status of their patients. In this regard, the study of Hayek et al. showed that the physicians recorded patients' pharmaceutical prescriptions in the computerized system of their clinics, and these requests had an integrated relation with the electronic medical record of their patients, and the requests were forwarded to the pharmacies after checking the pharmaceutical interferences and then the patients received their pharmaceutical prescriptions after the reference to the pharmacies (24).

\subsection{Limitation}

The results of this study should be interpreted with caution because the study was conducted using a researcher made questionnaire. Also, non-generalizable results of the study, because of it being done in a city, is of the other limitations of this study. However, the study results were in line with other studies in this field.

\section{Conclusions}

The results showed that the physicians used, in some ways, health information technology for the reduction of medical risks and the increase of the patients' safety by collecting the medical data of patients and the rapid and apropos recovering of the data for adaptation of clinical decisions. This status of systems is for different reasons, such as lack of physicians' familiarity and knowledge of advanced technology in the health department, and lack of necessary substructures for the implementation of these systems. Therefore, the management of the patients' safety and the physician-patient electronic communication, can be improved by applying the new technologies in ambulatory care centers.

\section{Acknowledgments:}

Research reported in this publication was supported by a grant [number: 959] from the Semnan University of Medical Sciences, Semnan, Iran. We would like to thank the clinical research development unit of Kowsar / Amiralmomenin Educational, Research and Therapeutic Centers of Semnan University of Medical Sciences for providing facilities to this work. Researchers would like to thank all the physicians of Semnan for participating in this study

\section{Conflict of Interest:}

There is no conflict of interest to be declared.

\section{Authors' contributions:}

All authors contributed to this project and article equally. All authors read and approved the final manuscript. 


\section{References:}

1) Sadoughi F SM, Ehteshami A, Aminpour F. health information technology. 2014: 4.

2) Bates DW, Cohen M, Leape LL, Overhage JM, Shabot MM, Sheridan T. Reducing the frequency of errors in medicine using information technology. J Am Med Inform Assoc. 2001; 8(4): 299-308. PMID: 11418536, PMCID: PMC130074.

3) Bello IS, Arogundade FA, Sanusi AA, Ezeoma IT, Abioye-Kuteyi EA, Akinsola A. Knowledge and utilization of Information Technology among health care professionals and students in Ile-Ife, Nigeria: a case study of a university teaching hospital. J Med Internet Res. 2004; 6(4): e45. doi: 10.2196/jmir.6.4.e45. PMID: 15631969, PMCID: PMC1550621.

4) Sinha R. Impact of health information technology in public health. Sri Lanka Journal of Bio-Medical Informatics. 2010; 1(4). doi: 10.4038/sljbmi.v1i4.2239.

5) Kaushal R, Shojania KG, Bates DW. Effects of computerized physician order entry and clinical decision support systems on medication safety: a systematic review. Arch Intern Med. 2003; 163(12): 1409-16. doi: 10.1001/archinte.163.12.1409. PMID: 12824090.

6) Kruse CS, Kristof C, Jones B, Mitchell E, Martinez A. Barriers to Electronic Health Record Adoption: a Systematic Literature Review. J Med Syst. 2016; 40(12): 252. doi: 10.1007/s10916-016-0628-9. PMID: 27714560, PMCID: PMC5054043.

7) Himmelstein DU, Wright A, Woolhandler S. Hospital computing and the costs and quality of care: a national study. The American Journal of Medicine. 2010; 123(1): 40-6. doi: 10.1016/j.amjmed.2009.09.004.

8) Mennemeyer ST, Menachemi N, Rahurkar S, Ford EW. Impact of the HITECH Act on physicians' adoption of electronic health records. J Am Med Inform Assoc. 2016; 23(2): 375-9. doi: 10.1093/jamia/ocv103. PMID: 26228764.

9) Persell SD, Kaiser D, Dolan NC, Andrews B, Levi S, Khandekar J, et al. Changes in performance after implementation of a multifaceted electronic-health-record-based quality improvement system. Med Care. 2011; 49(2): 117-25. doi: 10.1097/MLR.0b013e318202913d. PMID: 21178789.

10) Sood HS, McNeil K. How is health information technology changing the way we deliver NHS hospital care? Future Hospital Journal. 2017; 4(2): 117-20. doi: 10.7861/futurehosp.4-2-117.

11) Buntin MB, Burke MF, Hoaglin MC, Blumenthal D. The benefits of health information technology: a review of the recent literature shows predominantly positive results. Health Aff (Millwood). 2011; 30(3): 464-71. doi: 10.1377/hlthaff.2011.0178. PMID: 21383365.

12) Police RL, Foster T, Wong KS. Adoption and use of health information technology in physician practice organisations: systematic review. Inform Prim Care. 2010; 18(4): 245-58. PMID: 22040851.

13) Hsu J, Huang J, Fung V, Robertson N, Jimison H, Frankel R. Health information technology and physicianpatient interactions: impact of computers on communication during outpatient primary care visits. J Am Med Inform Assoc. 2005; 12(4): 474-80. doi: 10.1197/jamia.M1741. PMID: 15802484, PMCID: PMC1174892.

14) Hing ES, Burt CW, Woodwell DA. Electronic medical record use by office-based physicians and their practices: United States, 2006. Adv Data. 2007; (393): 1-7. PMID: 18019786.

15) Rittenhouse DR, Ramsay PP, Casalino LP, McClellan S, Kandel ZK, Shortell SM. Increased Health Information Technology Adoption and Use Among Small Primary Care Physician Practices Over Time: A National Cohort Study. Annals of family medicine. 2017; 15(1): 56-62. doi: 10.1370/afm.1992. PMID: 28376461, PMCID: PMC5217844.

16) Kahouei M, Asefi A, Davoodi Z, Mousavi RS. The prioritization of barrier and facilitators in physicians'adoption towards information technology in health area. Health Inf Manage. 2014; 11(5): 557.

17) Finet $P$, Jeannès RLB, Dameron $O$, Gibaud B. Review of current telemedicine applications for chronic diseases. Toward a more integrated system? IRBM. 2015; 36(3): 133-57. doi: 10.1016/j.irbm.2015.01.009.

18) Gaster B, Knight CL, DeWitt DE, Sheffield JV, Assefi NP, Buchwald D. Physicians' use of and attitudes toward electronic mail for patient communication. J Gen Intern Med. 2003; 18(5): 385-9. PMID: 12795738, PMCID: PMC1494854.

19) Brown J, Ryan C, Harris A. How doctors view and use social media: a national survey. J Med Internet Res. 2014; 16(12): e267. doi: 10.2196/jmir.3589. PMID: 25470407, PMCID: PMC4275505.

20) Kazemi A, Rabiei R, Moghaddasi H, Deimazar G. Pharmacy Information Systems in Teaching Hospitals: A Multi-dimensional Evaluation Study. Healthcare Informatics Research. 2016; 22(3): 231-7. doi: 10.4258/hir.2016.22.3.231. PMID: 27525164, PMCID: PMC4981583. 
21) Wager KA, Lee FW, Glaser JP. Health care information systems: a practical approach for health care management. John Wiley \& Sons; 2009.

22) Colpaert K, Decruyenaere J. Computerized physician order entry in critical care. Best Pract Res Clin Anaesthesiol. 2009; 23(1): 27-38. PMID: 19449614.

23) DesRoches CM, Campbell EG, Rao SR, Donelan K, Ferris TG, Jha A, et al. Electronic health records in ambulatory care--a national survey of physicians. The New England journal of medicine. 2008; 359(1): 5060. doi: 10.1056/NEJMsa0802005. PMID: 18565855.

24) Hayek A, Joshi R, Usherwood T, Webster R, Kaur B, Saini B, et al. An integrated general practice and pharmacy-based intervention to promote the use of appropriate preventive medications among individuals at high cardiovascular disease risk: protocol for a cluster randomized controlled trial. Implement Sci. 2016; 11(1): 129. doi: 10.1186/s13012-016-0488-1. PMID: 27664074, PMCID: PMC5034506. 